\title{
Examining the Internet as a Strategic Corporate Communication Tool in Public Relations Practice
}

\author{
Nkem Jacobs \\ Kiyi Concepts Limited, Lagos, Nigeria \\ Jeremiah Iyamabo (Corresponding author) \\ Lagos Business School, Pan-African University \\ KM 22, Lekki-Epe Expressway, Ajah, Lagos, Nigeria \\ Tel: 234-810-323-5988Ｅ-mail: jiyamabo@lbs.edu.ng \\ Olutayo Otubanjo \\ Lagos Business School, Pan-African University, Lagos, Nigeria
}

Received: May 21, 2013 Accepted: June 20, $2013 \quad$ Published: July 10, 2013

doi:10.5296/bmh.v1i2.3735

URL: http://dx.doi.org/10.5296/bmh.v1i2.3735

\begin{abstract}
The Internet as an innovative platform housing multiple channels of communication is largely responsible for the presence of businesses on the web space. As a result, businesses soon find themselves in a position, not only to feed Internet channels with content but also to manage the content vis-à-vis content on other platforms. In the context of the Nigerian financial services industry, this calls the attention of public relations (PR) practitioners who are positioned in the corporate affairs department to manage the image of the financial institutions they represent. The objective of this study, therefore, was to gain an understanding of the contributions in the literature with respect to the Internet as a communicative tool for businesses. Although the literature has little or no evidence from Nigerian markets, theoretical arguments indicate many uses of the Internet for business communication by PR practitioners resulting in a new communication model proposed by Hoffman\& Novak (1996). An attempt to situate these theoretical positions within a local context led the researchers to carry out a pilot study which revealed that there is a gap between internet channels initiated by business and the business objective of opening up such channels. As a result, there is a tendency of such channels to target the wrong audience - calling for the need for further research with empirical evidence.
\end{abstract}


Keywords: public relations, internet, corporate communication, media, image management 


\section{Introduction}

In the last decade the deployment of Information Communication and Technology (ICT) to industry and commerce has put the various functions of management on a different pedestal. In Nigeria there were just 200,000 Internet users in January 2001. But by the first quarter of 2011 the figure stood at about 44 million, indicating a growth of about $21,900 \%$ according to Internetworldstats.com. Consequently, growth of new technology has changed the way public relations practitioners ply their trade as they rely almost entirely on computers and other technological tools (including the Internet) to accomplish the traditional public relations tasks. In one survey carried out in the United States, about 88\% of public relations practitioners admitted that their departments use online services to support public relations objectives, and $87 \%$ indicated that individuals in their offices use online resources daily (Ryan, 1999). All over the world, the Internet alone constitutes a large share of new tools for reaching large and diversified publics. Among the mechanisms for making information electronically available to the public, which public relations practitioners have now become fond of include specialty web sites, corporate web sites and electronic publications (Shim, 2002). Also social media such as Facebook, Twitter, Flicker, etc. have all risen in importance and usage.

In this regard, it may be safe to conclude that public relations have been revolutionized by the use of Internet tools. Perhaps the aspect of public relations most influenced by the Internet is media relations. According to Hill \& White (2000) websites are potential sources of information for media men and offer easy access to journalists. Bobbitt (1995) points out that the importance of gate keeping by the media declines in an online environment and particularly so because of the open nature of the mechanism in terms of access and usage. In the same vein Cadence \& Niranjan (2000) posit that the Internet allows controlled communication to flow directly between organizations and the public without the gate keeping function of other media (Shim, 2002). Communication scholars also predict that as technological changes continue to increase, the impact on public relations will continue to rise as well (Pavlik \&Dozier, 1996). Newsom, van Slyke \& Kruckeberg (2000) suggest that it is nearly impossible these days to effectively practise public relations without using the Internet. This position is shared by Wilcox, Ault \&Agee (1998) who suggest that cyberspace communication is a significant, swiftly expanding tool for public relations practitioners. Looking back thirteen years and seeing the way things have turned out today, it is clear that this position was nothing short of an accurate prophecy. In a survey of professionals in eight countries including the United States, Bunz (1998) found that the Internet was having a strong impact on public relations.

Among other findings, Bunz (1998) reported that two-way communication models were being improved and facilitated through functions such as e-mail and web platforms. Available evidence shows that public relations professionals, journalists, and advertisers use the new technologies to work more effectively, faster, and more efficiently, and reduce costs in the public relations practices (Pavlik \& Dozier, 1996). However, this has sparked off debate in some scholarly quarters as some believe that overall cost of public relations goes up as a result of the application of the Internet because the acquisition of the basic infrastructure usually do not come cheap. This explains why small and medium enterprises lag behind in the deployment of Internet technologies. Despite the growing interest by scholars and practitioners in Internet 
public relations in the world, empirical research of the trend in Nigeria is virtually non-existent. Most of the literatures are European, Asian or American in content and in perception, thereby leaving the role of Internet in public relations in Nigeria unexplored. This is a serious short-coming and presents a major obstacle to the progress of public relations practice in Nigeria. The concern in this study is therefore to understand how public relations practitioners in Nigerian banks perceive the Internet as a public relations tool. The findings could further spark off further research based on empirical evidence - particularly research efforts on the practice of public relations in the Nigerian environment.

\section{Literature Review}

\subsection{The Internet and Business in Nigeria}

Various studies indicate that the Internet has become ubiquitous in business, affecting every facet in ways that has never before been experienced. This overwhelming impact arose from the Internet's desirable characteristics, particularly its interactive, real-time, availability to millions of people around the world at the same time as well as its ability to store huge volume of data in virtual locations, its ability to serve as a platform for transactions to various online channels and the low entry and establishment costs, among others identified by Peterson, Balasubramanian \& Bronnenberg (1997). Nigerian businesses have embraced the Internet culture more in the last ten years but the rate of penetration is far from global best standards due to a combination of factors including high cost, poor infrastructure and inadequate technical manpower. As at March 31, 2011 there were about 44 million people with web access according to internetworldstats.com. This shows a penetration per population of about $28 \%$. Despite this encouraging run, little is known about to what extent Internet technology affects functional areas of management including human resources management, customer relations, investor relations, and public relations among others. Information is even more exiguous for corporate Nigeria. However, in Europe and the US, much work has been done by scholars. It is therefore necessary to examine the trend in Nigeria.

The impact of the Internet on business strategy has been on the rise since it was freed for commercial applications in 1992.Practically all Internet users are potential customers to any business with a web presence. It therefore becomes imperative that seeking web presence should be a major preoccupation of any one in business. Beside its facilitations in the area of providing prompt and efficient customer service and efficient transaction mechanism, the Internet provides a low cost gateway into international markets. The Internet extends market reach and operational efficiency of enterprises (Dholakia \& Kshetri, 2002), implying that the Internet provides firms the opportunity to alter market focus, product policy and size orientation overnight. Specific tasks that fall under these include sending and receiving emails; conducting research and shopping for goods and services (Dholakia \& Kshetri, 2002).

\subsection{The Internet and Corporate Communication}

Scholars agree that the impact the Internet has had on relationship marketing has been enormous because it enhances commitment, satisfaction and trust. This is also as a result of its desirable characteristics discussed earlier such as its interactive nature and the constant 
availability of information. The Internet helps businesses provide value to customers and serve them as individuals. This makes them to feel personally wanted and close to the business which is key to sustained patronage. Experts agree that taking every step to be close to customers and to attend to their needs all the time pays huge dividends in terms of patronage.

On its part, technology has altered human resource management especially from the perspective of employee communication and motivation, training, orientation and mentoring. Innovative approaches driven by online connectivity have simplified employee communications and has therefore shortened communication cycle time, reduced the cost of employee communications and enhanced distribution. As the corporate hierarchy flattens, decision making becomes faster leading to lower administration costs, improve employee communication and satisfaction, while at the same time reducing processing time so that management could be devoted to strategic business issues (Hawking, Stein \&Foster, 2004).

Through the process of 'disintermediation', coupled with the decentralisation of information, the Internet platform has created increased opportunities for professional service providers (e.g. stock brokers, real estate brokers, analysts and consultants) - especially in the financial markets - to deal with more informed customers. This is as much a benefit for the service providers as it is for customers. More customers become informed of the benefits of the financial markets, therefore are more willing to participate in financial markets rather than totally avoid it due to knowledge gap built on concepts, institutions and processes they otherwise would not understand. In addition, people can now act as their own market analysts, portfolio managers and traders; thereby creating another segment of the market that will subscribe to more specialised and advanced service from experts. Companies now post their financial results on the web - as part of efforts towards improving investment relations. With the assistance of investment-oriented discussion groups and websites, people get more information about business and finance. With all of the advantages, the possibility of unscrupulous activities pervading legitimate business on the Internet cannot be ruled out. Aside the challenge of providing adequate security measures to safeguard the interest of clients, it is increasingly necessary for organizations to create management systems for the interest of organizations against the damaging actions of Internet marauders.

The impact of the Internet on public relations is visible in the areas of research, media relations, communication strategy, crisis management and enhanced visibility. To the practitioner, it enhances personal sense of professionalism and craftsmanship. Despite these seemingly overt benefits, practitioners are often not given the requisite control over content with respect to the organizations they represent. This may be due to the dearth in understanding the need for image management via all or any platform through which the organization is represented. A crucial question is therefore, why there is such a gap if organizations know about the importance and benefits of the Internet. As pointed out earlier, there is a relatively low level of penetration of Internet accessibility in Nigeria compared to Western countries. Perhaps, due to this low penetration, organizations are yet to perceive the Internet as a platform where their key stakeholders (e.g. investors, suppliers, merchandisers, business travellers, HNIs, vendors, government officials/regulators) go to seek information about them - where information, when (and how they are) available, go a long way to influence the perception audiences will have of 
the organization. At present and at best, until this can be determined through empirical evidence, managers will tend to base their decisions on their old perceptions of the kind of platforms, mediums and channels that appeal to their kind of audiences where business is concerned. Nevertheless, the Internet represents new communications paradigms which heralds a new era of two-way symmetrical public relations.

\subsection{The Internet and Public Relations}

The role of public relations in the discharge of day-to-day tasks, including research, training, and professional development are significant. Despite this, the growth of its deployment has been slow due to a lot of reasons including that its proliferation is largely driven by commercial interests. Again, public relations professionals have not done enough to educate themselves about the technology and have therefore remained perpetually in a "learning curve" (Johnson, 1997) while their counterparts on other branches of marketing communications have gone ahead. For this reason, several organisations' websites that should be discharging public relations functions are left ineffective. Avila \& Sherwin (1997) maintain that most of them were set up just because management of the organisations feared that they would be left behind if they did not rather than to help achieve specific business objectives. This explains why web sites of several companies have remained underdeveloped and unable to foster meaningful two-way interaction between organisations and their publics. Nonetheless, the Internet has become a powerful tool in the hands of stakeholder publics, especially activist groups.

The Internet has also advanced the practice of corporate communications by improving on the speed of sharing content, the nature of the message and the target audience. Internet driven corporate communications is therefore characterised both by monologic and dialogic, high speed narrowcasting of customized messages as against the erstwhile singularly monologic, low speed mass communication via traditional media. Holtz (1998) summarized how the Internet has changed communications in four ways, namely: 1) it is no longer characterized by the traditional "few- to-many" but has changed to "many-to-many" since anyone with an access can publish his/her views to highly targeted audiences; 2) communication is receiver-driven or self-administered. In other words users can pull out whatever they like and ignore the rest; 3) communication is access driven; that is, information must be made available when interested stakeholder publics want them; 4) communicators now need to reach people on individual basis; that is, there is high need for personalization irrespective of how heterogeneous the audience may be.

Although the Internet offers many opportunities to organisations to build mutually beneficial relationships with key publics, there is the great danger that it easily becomes a destructive tool in the hands of disgruntled stakeholders publics including journalists, activists and competitors who may use it to spread half-truths and sometimes, absolute falsehood. Ghost-user techniques are also deployed by disgruntled members of the public. This is facilitated by the challenge of hidden identity over the Internet. As a result, negative views of an organization expressed over the Internet may not necessarily represent the views of the corresponding number of users but of one user manifested as many users. As Internet security companies continue to find solutions to multiple identities over the Internet, it becomes even more pertinent for firms to be very 
sensitive about how information over the Internet space is managed.

The Internet is also changing the rules of communication engagement as it affects the position of organisations and their publics in the communication flow structure. The publics now have greater say on how the image of an organisation should be judged and this presents special challenges to organisations. Being an active platform the Internet is "populated" by people who are interested in issues and actively speak for or against such issues. It is therefore very difficult to suppress adverse opinions. In fact one of the major effects of the Internet is to speed up the formation of powerful activist groups in online debates in a sort of electronic "town hall meeting" were the fate of organisations could easily be decided with the whole world watching. Activists have successfully used the Internet to strengthen their position against strong commercial organisations. This means that the Internet is a powerful tool in the hands of both the big and the small. Only those who can constantly negotiate the tide of perception management through effective communication, mediation, and negotiation, by possessing the technical skills of internet usage as well as understanding the capabilities and limitations of internet platforms can significantly alter the web of stakeholder networks and power dynamics between activists and organisations (Coombs, 1998) while at the same time providing the value of remaining profitable for the organization.

The growth of online communities coincides with the maturing of the Internet. Online newsgroups help practitioners exchange information, practical experiences, and advice as well as to create online forums where issues are often discussed and debated. In essence, they serve as knowledge sharing centres. Setting up online communities of users around their services enables organisations to add a personal touch and human interaction to their services. Online communities further fragments the market and shifts power from marketers to consumers. It is necessary for public relations practitioners to monitor communities in order to put them to good use by timely responding to issues or subtly promoting their organisations' interests.

Part of the critical functions of PR practitioners is media relations. Just as journalists regularly source information from web sites and use emails and online groups to reach organisations, PR practitioners, themselves regularly contact media houses through emails and social networks including chat rooms. With the Internet, the discharge of the gate keeping function is further enhanced since the Internet provides more communication channels for the dissemination of information. As much as academic scholars and critics criticize the tendency of journalists to frame the news or messages to suit particular agendum, scholars also agree that media framing is inevitable to media practice - just as it is inevitable in the everyday points of interaction among individuals. Taking the speed of the Internet and the simultaneous dissemination it allows, it becomes even more pertinent for PR practitioners to harness the framing of messages for the benefits of their organizations. This can only be achieved with PR practitioners are coordinate the media framing process as much as possible.

On a final note, the Internet facilitates public relations due to its interactive function. Steur (1992) defined interactivity as the extent to which users can participate in modifying the form and content of a mediated environment in real time, and this enables users to select, search, edit, and modify the form and content of mediated messages by themselves. Interactivity creates 
avenue for immediate, two-way interaction, which promotes reciprocal two-way communication, between organizations and their publics. When visitors leave feedback (responses) on their web sites, organizations can leverage on this to develop long-term relationships with these publics due to the Internet's two-way interactive characteristics.

\section{Theory Integration: Social Systems Theory}

\subsection{Theoretical Foundation}

A good number of theories may explain the interaction of PR and corporate communications using the internet as a mitigating platform. However, systems theory appears to be most adequate for defining this relationship. In the first place, PR is often defined from a systems perspective because much of its activities are carried out in organisations with organised and systematic environments. The systems theory emphasizes the importance of equilibrium, balance and interdependence that construct society. Society is usually regarded as an integral whole, and the various subsystems work together to keep the whole in balance. The system's primary function is to maintain itself, therefore the interactions of the system (mechanical, organic and social) and the environment, ultimately defines the system (Mersham, et al, 1995; Gregory, 1999). Systems can be closed or open. A closed system is mechanistic in nature whereas an open system could be organic or adaptive. Open systems exchange energy, material and information with systems in their environments while closed systems seal their boundaries and do not exchange energy or information with their environment (Spicer, 1997; Gregory, 1999). They adjust and adapt to contract or accommodate environmental variations. The ultimate goal of the system is to survive. Therefore interaction with the environment is necessary to maintain balance (Gregory, 1999; Cutlip, Center \& Broom, 2000).

An organization such as a bank can be viewed from a system perspective. It is composed of interrelated units. Therefore, any single change in a subsystem will affect the entire system. Organizations exist in dynamic environments where they need to modify their internal processes and restructure themselves in response to the changing environment. The focus of systems thinking is on the interaction between the parts. One of the most prominent representatives of the systems theory view of society is Luhmann. In his thesis on Autopoiesis (Greek word for self-creation), systems theory was developed into a theory as networks of "self-organising, self-thematizing, self-legitimating, self-reference communication”. Luhmann views society as an increasingly complex and differentiated cybernetic construction of self-creation”, where social systems are grouped around their own meaning within a particular functional system. According to Luhmann in Holmstrom (1997), when two or more individuals' actions are connected, a social system that separates itself from its environment is formed. Initially, these social systems are merely interaction systems but later can become more formalized into an organization system. The most comprehensive social system is the society itself (van Heerden, 2004).

Social systems isolate themselves from other systems and take on their own life, establishing a difference between the system and its environment. Systems therefore function simultaneously as open and closed systems. They change and adapt into closed self-referential processes requiring an amount of openness. This distinction is achieved through meaning, and meaning is 
created through communication. Communication is coordinated by means of codes. The maintenance of social systems' boundaries is central to this theory. Social systems are thus clustered in functional systems with their respective symbolic communication mediums (Holmstrom, 1997). Buckley in Gregory (1999) embraced the adaptive model where organizations are invited to engage stakeholders, to create a process of shared meaning, which will change the organization's current form. The organization is part of a whole system which is interdependent, and where the relationship between the organization and its environment are subject to change.

\subsection{Social Systems Theory \& Public Relations}

Spicer (1997) argues that the systems theory is important for public relations in three ways. Initially, scholars were much concerned with studying an organization by largely focusing on the internal workings of the organization. Systems theory moved this locus to a focus on the interdependence of an organization and its environment. Secondly, systems theory guides research and theorizing in scientific communities. This theory is very prominent in the PR definitions, and the understanding of the concept is encapsulated by an emerging organizational view of the field through the general systems theory (Grunig, 1992; Pavlik, 1987 in Spicer, 1997). Public relations concepts such as boundary-spanning activities and adaptation to the environment reflect a general systems theory approach. Thirdly, the theory serves as a useful heuristic tool in assisting the public relations function to conceptualize the complex nature of organizational interdependencies. It also provides a framework for thinking about aspects of importance in understanding organizational PR decision-making and effectiveness. This type of thinking provides individuals with an understanding of the world as an interconnected whole (van Heerden, 2004).

Dozier in Grunig (1992) points out that definitions based on systems theory address various roles that the public relations practice needs to fulfil. The Systems theory provides an understanding of the importance of adapting to the increasingly unstable and threatening environments organizations have to function in. In the conceptualization of the strategic role of the PR manager, Steiner (2001) concludes that the systems theory provides an ideal approach for the development of the 'strategist' role. He explains that the various elements of the open systems mechanism emphasizes the process input, throughput, output and feedback by binding the external and the internal environment with the organization. PR facilitates the process and the Internet provides added impetus.

In support of this theory, Hoffman\& Novak’s (1996) many-to-many Internet communication model, addresses the inadequacies of the age-long one-to-many model. The model depicts four main characteristics as follows: 1) consumers can interact with the medium and with each other; 2) firms can provide content to the medium and interact with each other; 3) firms and consumers can interact; 4) consumers can provide commercially-oriented content to the medium.

The process shown in Figure 1below is a central mechanism for understanding organisational communication. Content is generated between the consumer and the medium and between the firm and the medium. These are depicted with two-sided arrows indicating bi-directional flow 


\section{Macrothink}

(interaction). This shows that between the firm and the medium and between the consumer and the medium, flow is reversible to make the consumer or the medium the source of the message. The implication of this is that various sources (consumer, firm, etc) can engage various other sources in the communication flow. However, there is no direct interaction between consumers. But when the content hits the medium it becomes transformed and other consumers become involved, and may take in the message or transform and transfer it through the medium to other parties. According to this model, the primary relationships are not between sender and receiver, but with the computer-mediated environment with which they interact. Content is not merely transmitted from sender to a receiver, instead, mediated environments are created by participants and then experienced. Firms interact with consumers as well as with each other making communication much more complete and 'mass' in nature.

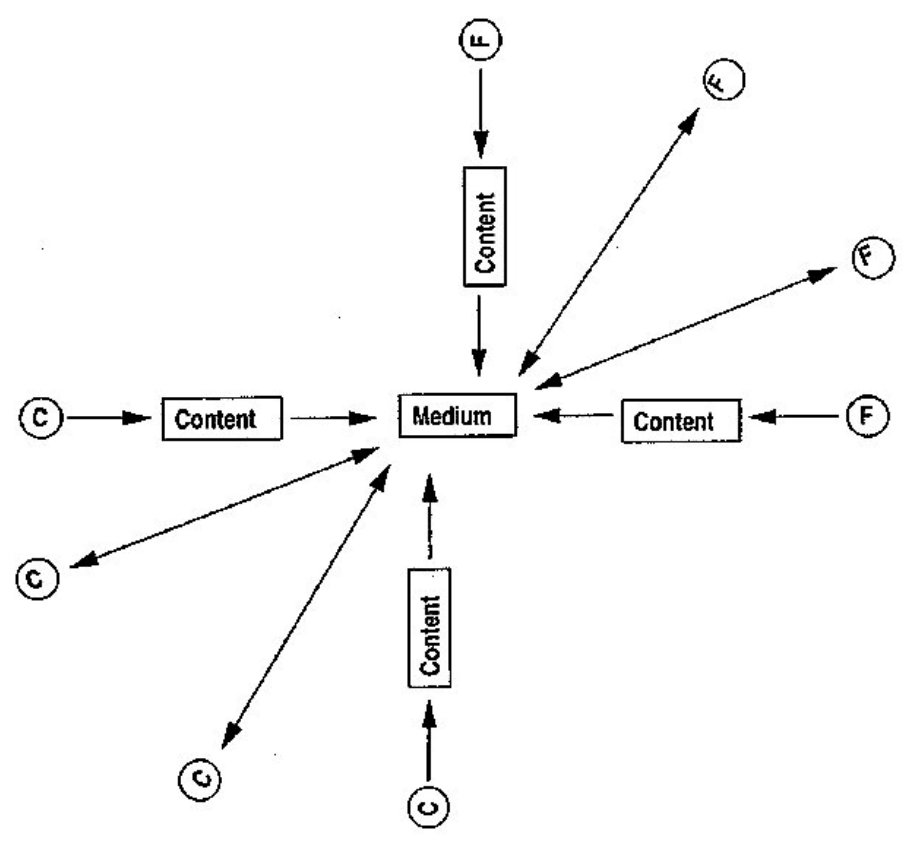

Figure 1. A model of marketing communications in a hypermedia computer-mediated environment (Hoffmann \& Novak, 1996)

With a new communication technology such as the Internet, it is necessary for scholars to rethink theories and postulations. Morris\& Ogan (1996) notes that when the Internet is conceptualized as a mass medium, it becomes clear that neither 'mass' nor 'medium' can be precisely defined for all situations, but instead must be continuously re-articulated depending on the situation. Adopting the Internet as a mass communication medium therefore does not automatically resolve outstanding issues such as the nature of communicative content. It is difficult for now to ascertain who sets the agenda as the Internet is somehow out of control by its very nature. There is also the issue of ethics and credibility. It is difficult, at present, for the Internet to make claims about the veracity of its information, which is one of the characteristics of traditional mass media that has made them so effective over the years. Everyone can post 
content on the Internet no matter whether it is correct or not. Nevertheless, the many-to-many model is changing the face of communication theory. It has become a major model for analyzing the type of organisational communication that can occur when the Internet is the major medium.

\section{Methodology}

In an attempt to validate the theoretical positions in sections $\mathrm{xxx}$ of this paper within the context of corporate Nigeria - particularly the financial services industry, the authors carried out a pilot study to determine the position of PR practice in Nigeria from the position of PR practitioners who are responsible for managing the image-perception of Nigeria's banking industry. There are 24 money deposit banks and four other related institutions viz: the Central bank of Nigeria (CBN), Chartered Institute of Bankers of Nigeria (CIBN), Nigeria Deposit Insurance Corporation (NDIC) and the Bank of Industry (BOI) - bringing the total number of unique institutions to 28. A sample size was first determined based on the discretion of the researchers. This judgment was also based on PR practitioners who were accredited members of the Association of Corporate Affairs Managers of Banks (ACAMB). The sample was therefore determined as $n=28$. Questionnaire items were designed as open-ended questions. This enabled the respondents to respond as freely to each questionnaire item and as expressly as they could. Responses from all 28 respondents were then collated and distilled to reveal incidents of coherence. The results were finally represented in Tables $1-3$ in subsequent paragraphs.

The questionnaire was first administered via email which was followed up by personal delivery of copies to members who did not respond initially. Out of the sample of 28 selected for participation in the study eight (8) or $28.6 \%$ were female public relations practitioners while 20 or $71.4 \%$ were males. Four (14.3\%) copies of the questionnaire were not returned for analysis. A total of 24 copies of completed questionnaire were received, thus showing a response rate of about $85.7 \%$. The subjects' average age was 32.6 years old, ranging from 26 to 47 years old. On the average, the subjects had worked for 5.1 years in public relations. About $33.33 \%$ or eight (8) of the subjects had at least a bachelor's degree while $66.7 \%$ or 16 of the subjects had master's degree. Sixteen (16) subjects (66.7\%) had some media experience. A total of 14 respondents were heads of public relations units/departments $(55.3 \%)$ of those who returned their questionnaire while $10(41.7 \%)$ were members of the public relations team.

\section{Discussion of Findings}

Three categories of questions (i.e. Tables 2 -4) representing four, fourteen and three questions respectively constituted the questionnaire items on PR practice and Internet use for corporate communication in Nigeria. The three questionnaire categories were: 1) the respondents' understanding of the role of the Internet in general business landscape in Nigeria; 2) PR activities carried out on the Internet by PR practitioners, and 3) the role of the Internet with respect to media relations in Nigeria. Table 1 represents a general survey of PR practitioners on the department or unit currently responsible for managing content on corporate websites. The aim was to understand the current position in corporate organizations across the financial services industry in Nigeria. Descriptive data representing the respondents' responses were 
also computed to determine the percentages of representation. Interpretation of each of the question categories was finally carried out based on the descriptive statistics.

Table 1. Department responsible for content on corporate websites

\begin{tabular}{lll}
\hline & Frequency & $\%$ \\
\hline Computer/ICT & 10 & 41.7 \\
Marketing & 2 & 8.3 \\
PR/Corporate Affairs & 9 & 37.5 \\
Administrative & 3 & 12.5 \\
\hline
\end{tabular}

Table 1 above shoes responses on the department managing content on corporate websites.

The table below indicates that the control and management of content on corporate websites is in the hands of technical people more than public relations professionals. Ten (41.7\%) subjects agreed that the Computer/IT department is responsible for their organisation's websites thus exercising greater control than any other professional group. Public relations professionals are next in line in terms of management and control of corporate websites with nine (37.5\%) subjects agreeing they control their organisations' websites. Admin and marketing departments are the least considered for this task with $12.5 \%$ and $8.3 \%$ scores respectively.

Table 2. Role of the Internet in business generally

\begin{tabular}{llll}
\hline & & Frequency & $\%$ \\
\hline $\begin{array}{l}\text { Enhanced resource allocation and operational } \\
\text { efficiency }\end{array}$ & 21 & 87.5 \\
Improved internal cohesion and team building & 20 & 83.3 \\
Enhanced investors' interest and purchase of shares & 9 & 37.5 \\
Enhanced customer understanding and preference & 9 & 37.5 \\
\hline
\end{tabular}

Table 2 above illustrates practitioners' perception of how the Internet facilitates Nigerian businesses.

With respect to the Internet's impact on business generally, 21 subjects (87.5\%) agreed that the Internet has enhanced resource allocation and operational efficiency of their organisations while 83.3\% (20 subjects) said it had improved internal cohesion and team building. Just nine (9) subjects (37.5\%) each agreed that the Internet has enhanced investor interest and purchase of their organisations' shares and enhanced customer understanding and preference. This result indicates that the Internet has strong effects on business strategy and human capital management but does not exert as much impact on investors and customers relationships and interactions. 
Table 3. Public relations activities carried out with the Internet

\begin{tabular}{lll}
\hline & Frequency & $\%$ \\
\hline Information searching & 23 & 95.8 \\
Sending and receiving e-mail & 24 & 100.0 \\
Maintaining media contacts & 23 & 95.8 \\
Monitoring competition & 23 & 95.8 \\
Carrying out research & 24 & 100.0 \\
Recruiting PR employees & 2 & 8.3 \\
Monitoring the news & 24 & 100.0 \\
Contacting investors & 7 & 29.2 \\
Communicating with employees & 24 & 100.0 \\
Contacting customers & 23 & 95.8 \\
Crisis communication & 23 & 95.8 \\
Contacting professional PR associations & 7 & 29.2 \\
Adding/editing web contents & 23 & 95.8 \\
Contacting government officials & 3 & 12.5 \\
\hline
\end{tabular}

Table 3 above illustrates activities carried out by practitioners to facilitate corporate communication.

Respondents were asked the purposes for which they use the Internet. Table 2 above shows the percentage of responses indicating strong agreement for each purpose listed in the questionnaire. When respondents were asked to identify their purposes for using the Internet, top functions included sending/receiving e-mail, carrying out research, monitoring the news and communicating with employees, all of which scored (100\%) each. These were closely followed by information searching, maintaining media contacts, monitoring competition, contacting customers and crisis communication, all on 95.8\% score. Other uses rated quite insignificantly. Only 29.2\% (7 subjects) considered the Internet useful tool for contacting investors and contacting professional bodies. About 12.5\% and 8.3\% consider the Internet useful for contacting government officials and recruiting public relations employees respectively. The result therefore showed that contacting investors and government officials as well as recruiting public relations professionals and contacting members of professional bodies are not considered major uses of Internet for public relations by practitioners.

Table 4. Internet and media relations 
The Internet has changed how our organisation handles media 18 2013, Vol. 1, No. 2 contact and media relation activities.

The Internet has made it more difficult to control who deals with 10 75 the media on behalf of our organisation.

The effects of traditional media on public relations are stronger 23 than the Internet.

Table 4 above illustrates PR practitioners' perception on Internet use for media relations.

When asked to state how the Internet has affected media relations, 18 respondents (75\%) indicated that the Internet has changed how organizations handle media contacts and media relations activities while majority of the subjects do not believe that the Internet has made it difficult to control who deals with the media on behalf of the organization as only 10 believe otherwise. Majority of the subjects (23 or $95.8 \%$ ) believe that the effects of the traditional media on public relations are stronger than that of the Internet. These responses indicate that while the practitioners admit the great impact of the Internet on media relations they do not see it as overwhelming thereby suggesting that physical correspondence inherent in traditional media is still effective notwithstanding the arrival of the Internet and its widespread deployment.

\section{Conclusion}

The literature enumerates the usefulness of the Internet in corporate communication and this is substantiated by the systems theory and the many-to-many marketing communication model proposed by Hoffman\& Novak (1996). As discussed in Section 2, there is a dearth of research focusing on Nigeria as an emerging market, and how the Internet - as a corporate communication tool - affects the behaviour of PR practitioners who manage the image of their respective organizations. There is also the concern of how the multiplicity of channels opened up to today's consumer provides many mediums through which today's consumer can access information of organisations with an online presence. This has thrown even more concern on how PR managers are able to manage the images of the organisations they represent across media within the context of the financial services industry in Nigeria.

Although the reasons proposed by Dholakia \& Kshetri (2002) as to why businesses go online are well acknowledged, they seem to be more generalised than suited to all contexts when the position of Avila \& Sherwin (1997) is taken into consideration. Their study indicate that, rather than for the purpose of achieving set-out business objectives, many organisations with an online presence find themselves in such a position because they do not want to be perceived as being left behind. One key question which arises for this behaviour is "to be perceived as being left out" to what end; to win positive perception of the general public or key stakeholders of the organization's business? As businesses become more and more sensitive about justifying cost-points, PR practitioners are may also be conscious about targeting the channels, which appeal to key business stakeholders.

The literature also proposes a third reason which seems at variance with the previous two 
enumerated in the preceding paragraphs; that slow adoption of the Internet as a corporate communication tool is largely due to PR practitioners stuck on the learning curve of ICT (inclusive of the Internet) compared to their counterparts in other areas of marketing communication (Johnson, 1997). As represented in Table 1 above, The ICT department is mostly responsible for content management across the financial services industry in Nigeria, with PR practitioners closely following behind. This indicates that currently, PR practitioners may not be well positioned to manage corporate content across industry. This is irrespective of the knowledge PR practitioners demonstrate with respect to how the internet can be used for corporate communication.

Finally, the high indication by PR practitioners that the Internet does not enhance "investors' interest and purchase of shares" indicates that there is a gap between the Internet as a platform and investors' ability to tune to that platform (see Tables 2 and 3). This could be because the kind of audience (investors) are yet to interact with the Internet at the level of making business decisions rather than over-reliance on traditional media as argued in section 2.2 above. Further research with empirical evidence is hereby recommended towards validating the findings from the pilot study - especially in the area of investor relations with regards to the Internet as a platform for multi-layer interaction.

\section{References}

Avila, E. N., \& Sherwin, G. R. (1997). Connecting online: creating a successful image on the internet. Oregon: The Oasis Press.

Bobbitt, R. (1995). An internet primer for public relations. Public Relations Quarterly, 40(3), 27-32.

Bunz, U. K. (1999). An international communications perspective on professional internet usage: a survey of public relations practitioners' usage of the internet in six European countries and Australia with comparisons to the United States. Paper presented at the Combined Southern and Central States Communication Conference. St. Louis.

Cadence, W., \& Niranjan, R. (2000). The world-wide-web as public relations medium: the use of research, planning, and evaluation in web site development. Public Relations Review, 25(4), 405-419.

Coombs, W. T. (1998). The internet as a potential equaliser: new leverage for confronting social irresponsibility. Public Relations Review, 24(3), 289-303. http://dx.doi.org/10.1016/S0363-8111(99)80141-6

Cutlip, S. M., Center, A. H., \& Broom, G. M. (2000). Effective Public Relations (8th ed.). New Jersey: Prentice-Hall.

Dholakia, R. R., \& Kshetri. (2004). Factors impacting the adoption of the internet among SMEs. Small Business Economics, 211-322. http://dx.doi.org/10.1023/B:SBEJ.0000032036.90353.1f 
Gregory, A. (1999). Systems theory and public relations practice. Journal of Communication Management, 4(3), 266-277. http://dx.doi.org/10.1108/eb023525

Grunig, J. E. (1992). Excellence in public relations and communication management. Routledge.

Hawking, P., Stein, A., \& Foster, S. (2004). e-HR and employee self service: a case study of a Victorian Public sector organisation. Journal of Issues in Informing Science and Information Technology, 1, 1019-1026.

Hill, L., \& White, C. (2000). Public relations practitioners’ perception of the world wide web as a communication tool. Public Relations Review, 26(1), 31-52. http://dx.doi.org/10.1016/S0363-8111(00)00029-1

Hoffman, D. L., \& Novak, H. T. P. (1997). A new marketing paradigm for electronic commerce. The Information Society, 13(1), 43-54.

Hoffman, D. L., \& Novak, T. P. (1996). Marketing in hypermedia computer-mediated environments: conceptual foundations. The Journal of Marketing, 50-68.

Holmstrom, S. (1997). An inter-subjective and a social systematic public relations paradigm. $\begin{array}{llll}\text { Journal of } \quad \text { Communication } & \text { Management, }\end{array}$ http://dx.doi.org/10.1108/eb023445

Holtz, S. (1998). Public Relations on the net: winning strategies to inform and influence the media, the investment community, the public, and more! New York: The American Management Association.

Johnson, M. A. (1997). Public relations practitioners and technology: practitioner perspectives. Journal of Public Relations Research, 9(3), 213-306.

Mersham, G. M., Rensburg, R. S., \& Skinner, J. C. (1995). Public relations development and social investment: a South African perspective. Pretoria: van Schiak Publishers.

Morris, M., \& Ogan, C. (1996). The Internet as mass medium. Journal of Computer - Mediated Communication, 1(4). http://dx.doi.org/10.1111/j.1460-2466.1996.tb01460.x

Newsom, D., vanSlyke J., \& Kruckeberg, D. (2000). This is public relations: the realities of public relations (7th ed.). California: Wadsworth.

Pavlik, J. V., \& Dozier, D. M. (1996). Managing the information superhighway: a report on the issues facing communications professionals. Florida: Institute for Public Relations Research and Education.

Peterson, R. A., Balasubramanian, S., \& Bronnenberg, B. J. (1997). Exploring the implications of the internet for consumer marketing. Journal of the Academy of Marketing Science, 25(4), 329-346. 
Ryan, M. (1999). The world wide web, online resources and public relationspractitioners: what they use and what they recommend. Paper Presented at the Annual Convention of the Association for Education in Journalism and Mass Communication, New Orleans, Los Angeles.

Shim, H. R. (2002). The internet as a public relations tool: study of Korean practitioners. Unpublished Master's Thesis, University of Florida.

Spicer, C. (1997). Organisational Public Relations. New Jersey: Lawrence Erlbaum Associates.

Steiner, C. F. (2001). How important is professionalism to corporate. An International Journal, 6(3), 150-156. http://dx.doi.org/10.1108/EUM0000000005739

Steur, J. (1992). Defining virtual reality: dimensions determining tele-presence. Journal of Communication, 42, 26-29. http://dx.doi.org/10.1111/j.1460-2466.1992.tb00812.x

van Heerden, G. (2004). The practice of public relations in Africa: a descriptive study. Unpublished Master's Thesis, University of Pretoria, South Africa.

Wilcox, D. K., Ault, P. H., \& Agee, W. K. (1998). Public relations: strategy and tactics. New York: Addison Wesley Longman.

\section{Copyright Disclaimer}

Copyright reserved by the author(s).

This article is an open-access article distributed under the terms and conditions of the Creative Commons Attribution license (http://creativecommons.org/licenses/by/3.0/). 